\title{
A METAFICÇÃO NO ROMANCE BUDAPESTE E NA SUA ADAPTAÇÃO FíLMICA
}

\author{
Janio Davila de Oliveira ${ }^{1}$
}

Resumo: O objetivo deste trabalho é fazer uma análise comparativa entre o romance Budapeste (2003), de Chico Buarque de Hollanda e sua adaptação fílmica (2009), dirigida por Walter Carvalho. O presente estudo propõe uma análise com enfoque no caráter metaficional das narrativas, elemento que na nossa visão é de grande importância na interpretação das estruturas das duas obras. Para a realização da análise, parte-se da proposta de Robert Stam (2006) de entender a adaptação fílmica como hipertexto. Logo, com base nessa categoria transtextual criada por Gerald Genette (2010), a adaptação fílmica deixa de ser associada à mera cópia e passa a gozar do status de obra original. Deste modo, buscaremos nas duas obras, Budapeste romance e Budapeste filme, entender a importância da metaficção e como ela foi tratada por Walter Carvalho ao ser transposta para a tela

Palavras-chave: Budapeste. Adaptação fílmica. Metaficção.

\begin{abstract}
The objective of this paper is to make na comparative analysis between the book Budapest (2003), by Chico Buarque de Hollanda and its filmic adaptation (2009), directed by Walter Carvalho. The present study proposes na analysis with a metafictional approach of its narrative, element that in our vision is of great matter in the interpretation of the structures of his works. For the accomplishment of the analysis, we'll start from Robert Stam (2006) proposal to understand the filmic adaptation as a hypertext. Therefore, with grounding in this transtextual category created by Gerald Genette (2010), a filmic adaptation is no longer associated to a mere copy and gains the status of an original work. Thus, we'll look for in both works, Budapest romance and Budapest film, to understand the importance of the metafiction and how it was handledby Walter Carvalho as being transposed to the screen.
\end{abstract}

Keywords: Budapest. Filmic Adaptation. Metafiction.

\footnotetext{
${ }^{1}$ Mestrando do Programa de pós-graduação em letras- estudos literários, da Universidade Federal de Santa Maria (UFSM). Bolsista Capes. Email: janio.davila@hotmail.com
} 


\section{Introdução}

O objetivo deste trabalho é apresentar uma análise comparativa que vem sendo realizada dentro da nossa pesquisa de mestrado sobre o romance Budapeste e sua adaptação fílmica realizada por Walter Carvalho em 2009. Buscaremos entender como a metaficção foi transposta para a versão fílmica. Em outras palavras, como diretor e roteirista conseguiram transpor para a tela temas tão próprios do romance.

Budapeste é o terceiro romance de Chico Buarque, lançado em 2003, destaca-se na obra elementos como fragmentação da identidade, questões de autoria, além de reflexões sobre o fazer literário. Romance de relativo sucesso entre o público, a obra conquistou diversos prêmios literários naquele ano e teve grande aceitação pela crítica.

O enredo trata da história de José Costa, um ghost-whiter, isto é, um escritor que escreve para que outros assinem a autoria. Assim, a personagem vive de escrever discursos, monografias acadêmicas, livros de memórias, entre outros escritos, em que a outros serão atribuídos os méritos. Portanto, temos um romance em que o protagonista é um escritor, ou seja, a ficção que faz dela mesma um tema, caraterística que teóricos como Gustavo Bernardo(2010),

Em relação à adaptação fílmica, traremos algumas teorias à respeito. Partiremos do pressuposto de que toda adaptação é uma nova criação artística. Uma obra nova, intertextual e que não deve ser reduzida a julgamentos de fidelidade ao texto original. Para isto, usaremos a obra de teóricos como Linda Hutcheon (1984), Robert Stam (1981), Ismael Xavier (2003) e Gerald Gennete (2010).

Ressaltamos que a pesquisa aqui exposta, ainda encontra-se em fase inicial de desenvolvimento, de modo que as análises do corpus ainda são precárias e com poucos resultados.

\section{A metaficção}


Quando consumismos uma obra de arte, seja ela literária, pictória, cinematográfica, musical ou de outra natureza, automaticamente assinamos um contrato de ilusão com o autor. Suspendemos nossa descrença, em troca, pedimos ao que autor nos conte uma mentira convincente.

Um paradigma realista de arte sempre buscou uma representação do mundo que conseguisse o máximo de aproximação com o que vulgarmente tratamos como o real. Deste modo, na maioria das vezes, o narrador do romance realista buscou uma problemática neutralidade, tentando apagar-se da narrativa. No cinema, JeanClaude Carrère (2015) assinala que os melhores diretores são os que não abusam da técnica, apagando-se do filme e deixando que a narrativa transcorra com 0 máximo de naturalidade possível.

Cada vez mais, é possível perceber que esse contrato que mencionamos entre autor e leitor/expectador da obra, vem sendo rompido, seja no cinema, no teatro ou na literatura, por parte de muitos escritores/diretores. Mas de que modo se dá esta quebra? Ela se dá através de um fenômeno que a maior parte dos teóricos nomeou de metaficção. O que é a metaficção?

No artigo intitulado A metaficção revisitada: uma introdução (2012), Zênia de Faria traça um breve histórico da problemática em torno deste tema.

A História Literária registra, desde o século XVI, no Ocidente, o surgimento de um tipo de texto ficcional que se volta sobre si mesmo, que é uma ficção que contém, em seu bojo, questionamentos ou comentários sobre seu estatuto linguístico, narrativo e sobre seu processo de produção e de recepção. [...] Desde o último quartel do século $X X$, metaficção, narrativa metaficcional, ficção ou narrativa pós-moderna são os termos predominantemente utilizados para designar tais tipos de narrativas (FARIA, 2012, p. 237-238).

Ou seja, a obra de arte afasta um pouco o seu caráter ilusionista e passa a discutir com o leitor diretamente o seu estatuto de ficção. São muitas as formas em que a metaficção pode se manifestar. Podemos ter um livro escrito dentro do livro que lemos, enquanto o narrador discute os problemas do fazer literário, podemos encontrar uma narrativa em que o narrador converse com o leitor diretamente, deixando claro que tudo que está sendo contato ali não passa de ficção.

David Lodge aponta que, apesar de a metaficção não ser uma invenção moderna, ela tem sido um recurso em que muitos romancistas contemporâneos se 
mostram interessados "porque se sentem sufocados com seus antecedentes literários, oprimidos pelo medo de que tudo que tenham a dizer já tenha sido dito antes e condenados pelo ambiente cultural moderno a ter essa essência (2009, p.214)"

Um dos estudos mais completos sobre a metaficção já publicados no Brasil foi o livro de Gustavo Bernardo, intitulado O livro da metaficção (2010). Na obra, Bernardo não deixa de fora o conflito entre realismo e metaficcionalidade.

Os defensores do paradigma realista se incomodam com a metaficção porque ela quebraria o contrato de ilusão entre o autor e o leitor, impedindo a suspensão da descrença tão necessária ao prazer da leitura. Entretanto o realismo pode ele mesmo ser percebido como uma espécie de máscara metafórica: quando desmascarado, revela-se metáfora (BERNARDO, 2010, p.40).

Logo, é possível perceber que a metaficção não deixa te ter um caráter problematizador. Até que ponto é eficiente esse contrato de ilusão que a literatura estabelece entre escritor e leitor? A ficção que trata de si mesma, que se autorreflete, não faz nada senão refletir sobre sua natureza, questionando seus limites e sua história.

\section{A metaficção no romance Budapeste}

Uma das primeiras recorrências de metaficção dentro de Budapeste é a escritura por José Costa do livro $O$ Ginógrafo, assinado por KasparKrebbe, um alemão que pagou para que Costa escrevesse sua autobiografia. A partir deste ponto, já passamos a refletir sobre as fronteiras entre realidade e ficção, no momento que uma autobiografia é escrita por um outro sujeito. Se no começo de Budapeste, o protagonista-narrador nos conta de sua chegada à capital húngara e sua fascinação pelo idioma húngaro, o início da biografia do alemão, não é muito diferente.

Eu era um jovem louro e saudável quando adentrei a baía de Guanabara, errei pelas ruas do Rio de Janeiro e conheci Teresa. Ao ouvir cantar Teresa, caí de amores pelo seu idioma (BUARQUE, 2003,p.38). 
Agora observemos o início de Budapeste:

Devia ser proibido debochar de quem se aventura em língua estrangeira. Certa manhã, ao deixar o metrô por engano numa estação azul igual à dela, com um nome semelhante à estação da casa dela, telefonei da rua e disse: aí estou chegando quase. Desconfiei na mesma hora que tinha falado besteira, porque a professora me pediu para repetir a sentença. Aí estou chegando quase (BUARQUE, 2003, p.5).

Podemos perceber que nas duas passagens, tanto a do livro que lemos, como a do livro que está dentro do livro, há um sujeito que se aventura em outro idioma e com uma mulher nativa deste idioma. O protagonista se apaixona pelo húngaro e passa a ter aulas com Kriska, por quem também se apaixona. Por sua vez, a história do alemão faz referência a um estrangeiro que chega no Rio de Janeiro e se apaixona pelo português e por uma falante do idioma. O nome Tereza é uma clara alusão intertextual à figura de Tereza dentro da literatura brasileira. $\mathrm{O}$ leitor mais atento, automaticamente faz associações, e ao ler sobre a ficção do alemão, é automaticamente lembrado de que o livro que lê também é uma fiç̧ão.

Após o lançamento de $O$ Ginógrafo, ficamos sabendo que o livro descrito, curiosamente, tem as mesmas características do livro que o leitor tem em mãos. Mais tarde, a capa do livro será explorada novamente.

O sucesso de $O$ Ginógrafo faz com que José Costa enfrente uma crise existencial, o que acaba refletindo na sua relação com a mulher Wanda, uma apresentadora de telejornal. É necessário atentarmos que em meio a todos estes acontecimentos, a breve passagem do protagonista por Budapeste, tal como o idioma Húngaro não saem de seu pensamento, de modo, que após diversos conflitos com Wanda, José Costa resolve voltar para país do leste do europeu. Lá conhece Kriska, sua professora de Húngaro com quem acaba se relacionado e morando junto. José costa se torna um expert em Húngaro, tornando-se agora um ghost-whiter no idioma estrangeiro. Neste ponto surge um outro livro dentro do livro: Os tercetos secretos. Um livro que Costa escreve para um poeta húngaro que há tempos não publica coisas relevantes.

Após idas e vindas entre Brasil e Hungria, José Costa vê os papéis ao qual está acostumado inverterem-se. Ao voltar para Budapeste, após uma mal sucedida 
estadia no Brasil, Costa volta para a Hungria e é recebido no aeroporto, onde se depara com o sucesso que um livro seu está fazendo na cidade. O livro chama-se Budapeste, e é mais uma vez quase idêntico ao que temos nas mãos. A narrativa em primeira pessoa que fez esquecer-nos em determinados momentos que estarmos diante de uma ficção, nos faz questionar sobre a autoria do livro que estamos lendo. Porém, o paratexto agora quebra esse ilusionismo.

A capa furta-cor, eu não entendia a cor daquela capa, o título Budapest, eu não entendia o nome ZsozeKósta ali impresso, eu não tinha escrito aquele livro. Eu não sabia o que estava acontecendo, aquela gente a minha volta, eu não tinha nada a ver com aquilo (BUARQUE, 2003, p.167).

Para aumentar ainda mais as dúvidas do leitor, o livro de Chico Buarque, encerra-se com o mesmo período que encerra o livro escrito por José Costa para o alemão: "E a mulher, do qual o leite eu sorvera, me deu beber a agua com que havia lavado sua blusa" (BUARQUE, 2003, p.174).

O livro encerra-se deixando o leitor ainda mais na dúvida sobre a veracidade das palavras do narrador José Costa (ou seria ZsozeKósta?). Teria sido o um escritor brasileiro que relatou a história de quando foi enganado ou, realmente, o livro que lemos foi escrito por um ghost-whiter, contando a vida de José costa? Ou ainda, a pergunta que nos oferece a resposta mais provável, não passaria tudo de uma ficção escrita por um autor do qual o nome pouco importa? São questões que mostram a razão e ser da metaficção, A ficção que se refere a si mesmo, que faz com que a sua escrita seja motivo da nossa reflexão tanto quanto a história contada por ela.

\section{Algumas teorias da adaptação}

A obra de Buarque foi adaptada para o cinema no ano de 2009 pelo diretor Walter Carvalho, com roteiros de Rita Buzzar. A partir das concepções de adaptação de Linda Hutcheon (2013) e Robert Stam (1981), a partir dos conceitos de transtextualidade elaborados por Gerald Gennete (2010) entendemos a adaptação como uma obra original e não como mera cópia ou extensão da obra de origem. Deste modo, a presente pesquisa busca entender como o caráter metaficional, tema 
tão caro à literatura contemporânea foi utilizado por Walter Carvalho na sua leitura fílmica de Budaeste.

No livro Uma teoria da adaptação (2013), Linda Hutcheon propõe uma divisão das formas de contar uma história conforme o seu modo de engajamento. Desta forma, segundo Hutcheon, esses modos de engajamento se dividem em contar, mostrar ou interagir. Portanto, segundo a autora, como exemplo do modo contar, temos a literatura narrativa, em que o campo da imaginação é controlado pelas palavras. No modo mostrar, destacam-se o cinema e as peças teatrais. Esse modo engloba as manifestações predominantemente imagéticas. Por fim, há o modo interagir, em que o espectador é convidado a participar do mundo da narrativa. , sendo que os videogames e o teatro participativo podem ser usados para exemplificar este desse modo.

A adaptação pode implicar, ou não, a mudança de um modo para outro. Um filme que venha a se tornar mais tarde uma peça teatral, é uma adaptação em que se mantém dentro do modo mostrar. Porém, contudo, a transposição da história de um romance para a forma de filme, implica uma mudança do modo contar para o modo mostrar, como é o caso do presente estudo.

Apesar de ser uma prática antiga e com valor artístico, pode-se perceber ainda muitos preconceitos em torno de obras que resultaram de processos de adaptação. Hutcheon (2013) busca desmistificar certos preconceitos que o tema abarca atualmente. Um deles, e talvez o maior de todos, é o de que a obra que deu origem à adaptação ou, a obra adaptada, como prefere chamar a autora, teria mais valor do que a obra que resultou deste processo. Conforme Hutcheon:

Em resumo, a adaptação pode ser descrita do seguinte modo: uma transposição declarada de uma ou mais obras reconhecíveis; um ato criativo e interpretativo de apropriação/recuperação; um engajamento intertextual extensivo com a obra adaptada (HUTCHEON, 2013, p.11).

Analisando as palavras de Hutcheon, percebe-se que a adaptação tem seu valor como obra de arte, sem ser secundária ou inferior. Assim como toda obra artística, a adaptação tem seu valor criativo, interpretativo e intertextual, estabelecendo um diálogo com a obra adaptada, sem que por isso sua "derivação" fique em segundo plano. 
Deste modo, partimos da concepção de que ao tratarmos de adaptações de romances para o cinema, não podemos negar o direito do cineasta à autoria. Sua obra não precisa, necessariamente, se preocupar-se com a fidelidade ao texto literário. Quem adapta está sempre transpondo para a tela a sua interpretação do texto, a sua leitura, ou seja, estará sempre envolvido envolvendo nisso um novo processo de criação..

A interação entre as mídias tornou mais difícil recusar o direito do cineasta à interpretação livre do romance ou peça teatral, e admitese até que ele pode inverter determinados efeitos, propor outra forma de entender certas passagens, alterar a hierarquia dos valores e redefinir o sentido da experiência das personagens. A fidelidade ao original deixa de ser o critério maior de juízo crítico, valendo mais a apreciação do filme como nova experiência que deve ter sua forma, e os sentidos nela implicados, julgados em seu próprio direito (XAVIER, 2003, p. 61-62).

Ao nos embasarmo-nos em concepções que tratem a adaptação como uma obra autônoma, original e de forte caráter intertextual, julgamos necessárias algumas considerações sobre esta relação dialógica estabelecida entre os textos. Não iremos fazer um percurso histórico do termo intertextualidade desde seu surgimento com Julia Kristeva a partir das leituras do dialogismo bakhtiniano de Bakhtin. Utilizaremos nesse projeto a teorização proposta por Gerald Gennete, que, em 1982, na sua obra Palimpsestos (2010), amplia a abrangência dos estudos da intertextualidade "deslocando-o [o termo] definitivamente da linguística para a poética" (SAMOYAOLT, 2008, p.28).

Gennete passa a considerar a intertextualidade como apenas mais uma entre cinco relações transtextuais que os textos podem estabelecer entre si. O teórico divide estas relações em: intertextualidade (presença de um texto em outro através da citação, da alusão, da paródia, etc), paratextualidade (elementos externos ao texto em si como título, subtítulos, capa, sinopse, etc), metatextualidade (comentário que une dois textos), a hipertextualidade (um texto derivado de um outro texto) e, o a última relação, a arqultextualidade (de caráter classificatório que determina o gênero do texto) (GENNETTE, 2010).

Daremos destaque aqui para a hipertextualidade, a perspectiva que assumiremos para a análise proposta. Segundo Gennete 
a hipertextualidade étoda relação que une um texto $B$ (que chamarei hipertexto) a um texto anterior $A$ (que, naturalmente, chamarei hipotexto12) do qual ele brota de uma forma que não é a do comentário. [...] Ela pode ser de uma outra ordem, em que $B$ não fale nada de $A$, no entanto nãopoderia existir daquela forma sem $A$, do qual ele resulta, ao fim de uma operação que qualificarei, provisoriamente ainda, de transformação, e que, portanto, ele evoca mais ou menos manifestadamente, sem necessariamente falar dele ou citá-lo (GENNETE, 2010, p.18).

A analogia utilizada por Gennete para uma exemplificação do conceito de hipertextualidade é a do Palimpsesto, um pergaminho que tem seu texto antigo raspado para que um novo seja escrito. Porém, através das transparências, ainda é possível ler o texto anterior.

Segundo Thaís Flores Nogueira Diniz (2005), o termo hipertextualidade é mais rico, quando se trata de adaptações cinematográficas, do que o tão difundindo intertextualidade. Os filmes adaptados da mesma obra podem ser vistos como hipertextos variáveis para um mesmo hipotexto. Porém, as adaptações anteriores, sempre farão parte de um hipotexto maior, que será sempre cumulativo e estará sempre a disposição dos novos adaptadores. (DINIZ, 2005)

\section{A metaficção no filme Budapeste}

Robert Stam assinala que o caráter auto-reflexivo é uma característica que podemos encontrar nos mais diversos meios artísticos, e o cinema não fica de fora, como o críticio nos lembra:.

A crítica fílmica também foi atingida pelo desconhecimento da tradição e das potencialidades criativas do antiilusionismo no cinema. Todo estudante de cinema se depara com um cortejo de críticos que, por razões nem sempre desinteressadas, são hostis ou cegos à ideia de auto-reflexividade da arte. [...] André Bazin resumiu este idela convencional do cinema como: "contar uma história numa linguagem transparente, clara e perfeita". E a transparência no cinema imlica uma técnica que busca obter a impressão contnua da realidade através de transições suaves e quase imperceptíveis de planos. Em resumo, uma técnica que não chama a atenção para si mesma (STAM, 1981, p. 55). 
Diferentemente de Godard, que fez do cinema um dos principais temas dos seus filmes, Walter Carvalho, não fez do filme uma reflexão sobre o fazer filmico, optando por uma adaptação mais fiel do que criativa, deste modo, conservando mais o caráter de reflexão literária do que propriamente cinematográfica.

A primeira cena do filme Budapeste é o protagonista se aproximando da câmera desfocada e que aos poucos vai tornando nítida sua imagem. A imagem vai se abrindo com o olho da câmera, tirando toda naturalidade da cena e explicitando a filmagem. Se o formato filme torna impossível o jogo com livros falando de livros, Walter Carvalho e Rita Buzzar mantém o caráter anti-ilusionista da obra, lembrando ao expectador de que o que está diante dele é um filme. Porém, apesar de a câmera se mostrar no filme durante algumas cenas, no geral Carvalho optou por transpor para a tela os problemas metaficionais do livro, ou seja, reflexões literárias e não cinematográficas.

Os espelhos, presentes em diversas cenas do filme, cumprem um papel importante na adaptação de Budapeste. Diversas vezes, e principalmente nas cenas íntimas, o protagonista está diante de espelhos, o que pode ser entendido como arepresentação de sua fragmentação como sujeito, visto que ele passa a transitar entre dois países, duas línguas, duas mulheres e, consequentemente duas identidades. Os espelhos, obviamente, também sugerem a auto-reflexividade da narrativa. Gustavo Bernardoutiliza a metáfora do espelho para falar sobre a metaficção.Segundo Bernardo:

O espelho da ficção não nos devolve a realidade refletida tal e qual: antes a inverte e depois nos leva para outro lugar. Este outro lugar se situa além da realidade de que partimos e além do espelho - além da ficção. [...] O que é a metaficção: Trata-se de um fenômeno estético autorreferente através do qual a ficção se duplica por dentro falando de si mesma (BERNARD, 2010, p.9).

Podemos perceber, a partir das palavras de Bernardo o quão simbólico é o significativo número de espelhos que aparecem durante a obra. O filme torna-se uma ficção que se duplica em diversos momentos, principalmente naqueles em que a câmera esta focalizando o protagonista.

A maior parte das questões sobre autoria são deixadas em aberto no romance e permanecem no filme. Porém uma das questões chaves do livro é 
resolvida pela obra fílmica. No romance não sabemos quem é o Sr..., responsável pela biografia de José Costa, porém o filme resolve esta questão, deixando claro, na cena da recepção no aeroporto, que o autor do livro é o marido do Kriska.

Em compensação, o filme insere uma outra questão através de um novo jogo anti-ilusionistaque cria novos níveis de metaficção. Em uma das cenas finais, o filme faz uma interessante quebra do realismo ao inserir o próprio Chico Buarque na obra. Ao chegar ao aeroporto de Budapeste, onde é agraciado pelo povo devido ao sucesso de "seu" livro, Costa é parado por Chico Buarque que com um sorriso irônico pede um autografo do livro. A ficção passa então a atingir um outro nível. Afinal, a aparição de Chico Buarque coloca em xeque até a autoria do ghot-whiter que escreveu a história de José Costa. Afinal, tal história foi escrita pelo ex-marido de Kriska ou por Chico Buarque? Por fim, o plano final mostra Costa lendo o livro frente a uma câmera, o que por sua vez, adiciona um terceiro nível de ficção. Acabamos de assistir uma filme que trata de um filme que problematiza a autoria de um livro que contém dentro de si outros livros.

\section{Considerações finais}

Como já frisamos na introdução, o presente artigo é resultado de uma pesquisa que está na sua fase inicial, de modo que ainda não foi possível chegar a resultados mais relevantes em relação à análise do corpus. A pesquisa até o momento está na fase de levantamento bibliográfico, para que possamos encontrar os referenciais teóricos que possam nos ajudar a analisar com mais perícia estas relações entre literatura e cinema.O que até aqui foi possível constatar é que a metaficção é um dos elementos fundamentais para a compreensão de Budapeste. Chico Buarque ao escrever Budapestefaz do seu romance uma reflexão sobre a literatura e a questão da autoria.

Em relação ao filme, o foi possível concluir até está etapa da pesquisa é que existe uma preocupação maior em ser fiel ao romance buarqueano do que criar novos jogos auto-reflexivos. Deste modo, o filme continua sendo metaficional, mas no caso, temos um filme que fala sobre o problema da autoria de livros e não, necessariamente, um filme que se auto refira, que traga para a tela problemas que questionem a sua própria natureza. 


\section{REFERÊNCIAS}

BERNARDO, Gustavo. O livro da metaficção. Rio de Janeiro: Tinta Negra Bazar, 2010.

BUARQUE, Chico. Budapeste. São Paulo: Companhia da Letras, 2003.

CARRIÈRE, Jean Claude. A linguagem secreta do cinema. Rio de Janeiro: NovaFronteira, 2015.

DINIZ, Thaís Flores Nogueira. Literatura e cinema: tradução, hipertextualidade, reciclagem. Belo Horizonte: Faculdade de Letras da UFMG, 2005.

FARIA, Zênia de. A metaficção revisitada: uma introdução.Signótica. v. 24, n. 1, jan./jun. p. 237-251. 2012. Disponível em:

<http://www.revistas.ufg.br/index.php/sig/article/view/18739/12292>. Acessoem: nov.2013.

GASS, William. Fiction and the fgures of life. Boston: Nonpareil Books, 1971.

GENETTE, Gérald. Palimpsestos. Belo Horizonte: Viva Voz, 2010.

HUTCHEON, Linda.Narcissistic narrative: the metaficcional paradox. New York; London: Methuen, 1984. . Uma teoria da adaptação.Florianópolis: UFSC, 2011.

LODGE, David. A arte da ficção. Porto Alegre: L\&PM, 2009.

SAMOYAULT, Tiphaine. A intertextualidade: memória da literatura. São Paulo: Aderaldo \& Rothschild, 2008.

STAM, Robert. O Espetáculo Interrompido: Literatura e cinema de desmistificação. Rio de Janeiro: Paz e Terra, 1981.

XAVIER, Ismail. Do texto ao filme: a trama, a cena e a construção do olhar no cinema. In:PELLEGRINI, Tânia. [et al.]. Literatura, cinema e televisão. São Paulo: Senac São Paulo: Instituto Itaú Cultural, 2003. p. 61-89.

\section{Referências fílmicas}

BUDAPESTE (Budapest) 2009. Direção de Walter Carvalho. Roteiro e produção de Rita Buzzar. Hungria/Brasil/Portugal: Imagem Filmes, 2009. 113 min. Sonoro e colorido. 
